\title{
Virtual mobility for students, going from distance learning to live participation
}

\author{
Karlis Valtins ${ }^{1}$, Natalja Muracova ${ }^{2}$ \\ ${ }^{1}$ International Cooperation and Foreign Students Department, Riga Technical University, \\ ${ }^{2}$ International Cooperation and Foreign Students Department, Riga Technical University
}

\section{Article Info}

Received Dec 10, 2018

\section{Keyword: \\ Online Learning \\ Student mobility \\ Virtual Mobility}

\begin{abstract}
Paper reviews differences between virtual mobility and distance learning, providing insight into current state of art for online learning in higher education. Authors analyze main barriers and obstacles for live virtual mobility to become a mainstream practice as well as justify the possible regions of operation. Summary is provided for the most visible pilot projects that have paved the way for the term virtual mobility to become an object of interest. Main impact factors are listed and the discussion part summarizes the future vision of live virtual student mobility in higher education.
\end{abstract}

\section{Corresponding Author:}

\section{First Author,}

International Cooperation and Foreign Students Department,

Riga Technical University,

1 Kronvalda Boulevard, Riga LV1010, Latvia

Email: Karlis.Valtins@rtu.lv

\section{Introduction}

Terms virtual student mobility and distance learning are not new, they have been evolving in scientific literature and education jour-nalism related to higher education arguably since University of Chicago launched its first college level distance learning programme in 1892. Authors of this article want to make a clear distinction between distance learning and virtual mobility, with the first being related to MOOC's, online learning supporting platforms (MOO-DLE, WEBCT, BLACKBOARD etc.), concept of being able to learn anywhere/anytime, autonomous learning, and the second being more related to virtualization of physical learning environment, live participation in ongoing classes, fully recognizable study experience and other features that are similar to the physical mobility of univer-sity students. Focus of this paper is on virtual mobility for exchange of university students. There are many different definitions for the term virtual mobility starting from mid 90ties, but most of them refer to technology as the mediator between faculty members and counterparts $[1,2,3]$. Recent study in Germany that focused on young adults (age 14-24) using the data from U.Move 2.0 project showed that there is a plausible link between physical and virtual mobility for digital natives of our era [4]. Purpose of this paper is to make awareness about importance of having live engagement into the classroom with other students that can result in positive interna-tional and academic experience.

\section{Not a new concept}

Reasoning behind mobility for university students is obvious and Erasmus programme that started in 1987 is one of the most signifi-cant evidences, providing to participants' international experience, language training, cultural experiences, new knowledge and new acquaintances. Although there have been many attempts to fully integrate distance learning in university curriculum by providing full degree programmes online, establishing open online learning cours-es free for all, encouraging university teachers to use online learning 
environments and corresponding tools, virtual mobility is not yet a mainstream practice. There have been several international initiatives and projects that have tried to put virtual mobility as a part of main-stream study process, most visible of them being:

- European Association of Distance Teaching Universities (1987). Website eadtu.eu reports that EADTU has a member-ship of fifteen institutions and fourteen national associations across 25 nations and its membership covers over 200 uni-versities and around 3 million students. In 2013, EADTU started the first pan European MOOC initiative called OpenupEd.

- CABWEB (2005) entitled "Collaboration across Boarders" was a project initiated by lecturers from the UK and Germany who shared an interest in student collaboration online. It had three main areas of cooperation: The HELP network of aca-demics, provision of collaboration spaces and support for organising and designing student collaborative activities, the JILID community, a global network of people who are inter-ested in the research and collaboration on intercultural aspects. Initiative have stopped and website cabweb.org is no longer active, but report by University of Salford in 2006 [5] speaks about 1921 student engaged in international collaborative ac-tivities in two and a half years.

- $\quad$ EdX (2012) which is founding platform for Massive Open Online Courses (MOOC's) was launched by Harvard Uni-versity in cooperation with Massachusetts Institute of Tech-nology. Website edx.org reports more than 1900 courses, 14 million users and 52 million enrolments across the courses.

- Erasmus+ Virtual Exchanges (2017). European Commission launched call for tenders to foster cooperation between EU and South Mediterranean region by linking countries young people aged 18 to 30 years with the help of virtual mobility possibilities. Tender was won by a consortium composed of Search for Common Ground (NGO), Anna Lindh Founda-tion (Euro-Mediterranean Foundation), UNIMED (Mediter-ranean Universities Union), Sharing Perspectives Foundation (NGO), Soliya (NGO), UNICollaboration (professional or-ganisation), Kiron Open Higher Education (social start-up), and Migration Matters (NGO). Website euro-pa.eu/youth/erasmusvirtual reports status: 3265 participants involved out of which 132 trained to develop a virtual ex-change.

- Several European Commission funded SOCRATES, Life-long learning programme and strategic partnership projects: ESMOS (Enhancing Student Mobility Through Online Sup-port, 2004-2006), TEACAMP (Teacher virtual campus: re-search, practice, apply, 2009-2011), EPICS (New Opportuni-ties For International Student Mobility, 2009-2011), UBI-CAMP (Integrated solution to virtual mobility barriers, 2012-2014), VMCOLAB (European Co-Laboratory for the Inte-gration of Virtual Mobility in Higher Education Innovation and Modernisation, 2012-2015), EMUNDUS (Fostering in-ternational Higher Education collaboration through ICT and Open Education, 2013-2015), OUVM (Opening Universities for Virtual Mobility, 2014 - 2016), OPENVM (Open Virtual Mobility, 2017-2020).

\section{Demand is outside $\mathbf{E U}$}

Student mobility in the EU has been made easy to access since launch of centralized Erasmus and various regional scholarship programmes. It is also possible for students to undergo mobility as "free movers", enrolling into corresponding EU University for one semester or a year on a basis of bilateral agreement. This justifies current approaches of higher education conduct where virtual part of studies is auxiliary to the physical studies. It is also easy to achieve international elements in higher education by publicly fund-ed internships, summer schools, visiting faculty, international stu-dent community at home University and more. These facts point towards understanding that biggest demand for virtual student mo-bility is located outside of EU. Authors of this paper have conduct-ed survey in a shape of questionnaire among more than 4000 teachers and students from Russia and Tajikistan during the year 2018 (in frameworks of Erasmus+ KA2 project EXTEND, Excellence in Engineering Education through Teacher Training and New Peda-gogic Approaches in Russia and Tajikistan, 2017-2020, reference number: 586060-EPP-1-2017-1-RO-EPPKA2-CBHE-JP) and results show the following patterns:

Teachers are concerned about the lack of time to fully use ICT tools in their everyday practice, as the burden of having many clas-ses is high. In the meantime, they are interested into learning more about how online tools could help them in the course delivery. When asked about the distance learning itself and most common tools, teachers did not provide clear evidence that they knew of live virtual mobility solutions and 
there was certain amount of scepti-cism about whereas it is needed to have distance learning elements in their courses.

Students (all three study levels) admit that international experi-ence, practical training and usage of ICT tools is important to have during their studies. Majority of students responded that most of study courses does not have international elements, virtual or dis-tance learning elements and that practical training could be more emphasized during their study programmes. Students, especially bachelor and master level students, stressed out the importance of teaching and learning methods, mentioning elements of active learn-ing, game based learning and simulation having a positive effect on the learning outcomes. This correlates also with the approaches forwards virtual practical training [6].

After European Commission announced a new activity in frame-work of Erasmus+ programme called "European Universities" in 2017, that aims to merge universities within the EU, adding to the competitiveness of EU higher education, it is even more apparent that the main demand for virtual mobility could be outside the EU. After the first European Universities will be formed, Commission aims to have at least 50\% of students have experienced mobility within the new established alliances by 2024. In regions outside the EU, university students have more limited opportunities to experi-ence mobility, selection procedures are not as transparent, and there are many groups of people with limited access to finances, travel and higher education in general. All these factors adds up and forms a thesis that main demand of virtual student mobility is located out-side the EU and industrialized, developed countries (i.e. Australia, New Zealand, Japan, USA, Canada).

\section{Virtual mobility in engineering sciences?}

It is simple to model virtual mobility solution in courses that are related to social sciences and humanities, but in the courses that are related to engineering disciplines studies typically include laboratory works, hardware based tests and practical assignments, which adds additional challenges to fully make virtual mobility applicable. Fair amount of research has been already dedicated to the virtualization processes in engineering sciences, just recently German researchers from Dortmund university analyzed remote and virtual labs for engineering education 4.0 [7] showing how practical lab tasks can be made available remotely using virtual simulations, virtual exper-imentation labs and supporting mobile application. In the whitepa-per for engineering education 4.0 experts also discuss concepts of virtual and remote labs [8,9], engineering education e-learning systems [10] and many more aspects of the engineering education future. There have been European Commission funded projects about virtual mobility in engineering education, for instance EVICAB (European Virtual Campus for Biomedical Engineering, 2006-2007) and SIM (Standardization in teaching of medicine, 2006 - 2008), second being devoted to scaling-up undergraduate medical education: Enabling virtual mobility by online elective courses, both have succeed in piloting virtual learning environment outside realm of social sciences and humanities. Researchers at University of Mostaganem in Algeria have made a model for re-mote laboratory suitable for low bandwidth connection, which is the case in many counties outside EU that would benefit the most from virtual mobility [11]. These findings suggest that if there will be a will to share hardware over the internet there is definitely a way.

\section{Online tools for virtual mobility}

Authors of this paper from February 2018 until June 2018 tested five most commonly used virtual conferencing software tools to see if they are fit for virtual mobility of university students. Testing was undertaken in cooperation with University of Kelaniya from Sri Lanka, where group of 19 undergraduate students participated in virtual mobility to Riga Technical University from Latvia and stud-ied course "General Sociology" (all students passed the course, going above previous virtual mobility pilot project general average of $48 \%$ efficiency, i.e. of students who enrolled graduating, effi-ciency percentage was dependent on the specific course [12]). The following virtual communication platforms were tested:

1) Zoom (zoom.us) - video communication platform, has possibility to connect 100 students simultaneously, capa-ble to connect to other video streaming tools from Face-book and YouTube.

2) Adobe Connect (adobe.com) - software for online con-ferences that offers virtual classrooms for students.

3) Skype (skype.com) - most popular online software for conference calls and virtual communication. Easy to use and available for computers and mobile devices. 
4) Webex (webex.com) - software for online video calls.

5) Google Hangouts (hangouts.google.com) - communica-tion platform.

All of the five solutions provided usability for virtual mobility with Adobe Connect providing the best functionality, such as rising hand to ask a question for a teacher, screen sharing for presentations, moderator mode allowing control over the sound settings for partic-ipants, saving chat log and other. Besides, in the student survey Adobe Connect showed the biggest satisfaction rating. Only down-side was the high cost structure of this solution in comparison to other four alternatives. Deeper analysis was not conducted, as the technical aspects were not the focus of the study.

\section{Biggest challanges}

Virtual mobility in the form of live participation still up to this day has small and high impact factors that transform into the main chal-lenges.

Small impact factors:

- $\quad$ Time difference between countries (can be tackled by both teachers and students).

- $\quad$ Formal enrolment (can be tackled by host institution, example can be taken from any distance learning course that institution is providing).

- Consultations and assistance during the semester (can be tackled by flexibility, email communication, additional tasks).

- $\quad$ Formal graduation (can be tackled by host institution, exam-ple can be taken from any distance learning course that insti-tution is providing).

- $\quad$ Student services (can be tackled by administration of the host institution).

High impact factors:

- Financing virtual mobility (incentives for teachers to take ad-ditional students, institutional sustainability strategy for growth of exchange student community. Can be solved by in-ternal or external sources of funding, EADTU experts esti-mate virtual mobility being more cost effective in comparison to physical mobility) [13].

- $\quad$ Examination (should be also virtual, emphasis needs to be on verifying the knowledge and ability to use knowledge rather than just memorizing information. Can be solved by project based examination, problem solving tasks, situation simula-tion tasks).

- Recognition of study period (students should be able to re-ceive recognition for the virtual mobility courses at their home institutions [14]. Additional academic recognition memorandums, listing all the transferrable courses and their descriptions can achieve this).

\section{Conclusions}

1. It is just a matter of time for live virtual mobility to establish itself in global higher education space. There are no alterna-tives for significant upscaling of students international expe-riences. Physical mobility is far too expensive to be in-creased by several orders of magnitude, while even in the most optimistic scenario overall student mobility worldwide still would stand around 3-6\% of all student population.

2. For live virtual mobility to work it has to go in a manner of bottom up approach - Individual cases (teachers with their courses) multiplying and growing to institutional practices. It would be hard to establish top to bottom approach, alt-hough majority of international initiatives are taking this par-ticular approach by establishing standardized structures. 
3. Technology for live virtual mobility is here for each and every academic discipline, providing standardized to tailor made tools, ranging from most simple and trivial online communication tools till sophisticated simulation and virtual reality software.

4. Main barriers are solvable having certain degree of interest and commitment to internationalization, technology and de-velopment of higher education by the main stakeholders: students (providing demand), teachers (allocating additional efforts), university management (prioritizing and approving virtual mobility schemes) and policy planners (giving ac-creditation to virtual mobility flows).

5. Future vision for virtual mobility includes studies on inte-grating active learning, project based learning, gamification and collaborative learning elements into virtual mobility models, advancing impact, outcomes and study process it-self.

\section{References}

[1] A.Maček, N. Ritonija, "Virtual Mobility in Higher Education - The Case of DOBA Faculty", Studies from Education and So-ciety (2016), ISBN 978-80-89691-38-8, pages 100-101.

[2] H. Bijnens, M. Boussemaere, K. Rajagopal, I. Op de Beeck, W.V. Petegem, "A Best Practice Manual”, European coopera-tion in education through virtual mobility (2007), pages 25-26., available online: http://www.virtualschoolsandcolleges.eu/images/9/9b/BM_handbook_final.pdf, last visit: 29.12.2018.

[3] S. G. Bunt-Kokhuis, "Academic Pilgrims: Faculty Mobility in the Virtual World", On the Horizon 9 (1) (1996, 2001), pages 1-4.

[4] K. Konrad, D. Wittowsky, "Virtual mobility and travel behaviour of young people - Connections of two dimensions of mobility", Research in Transportation Economics, SI: Frontiers in Transportation, Volume 68 (2018), page 14.

[5] F. Bell, E.Zaitseva, F.Thissen, J.Whatley, "CABWEB Portal - Online Activities in Support of Internationalising the Curriculum", Internationalisation of the Curriculum and Support for International Students (2006), pages 1-2.

[6] M. Vriens, W. Van Petegem, J. De Gruyter, I. Op de Beeck, "Virtual Mobility and Work Placements", Paper published in the conference proceedings of EDULearn10, International Conference on Education and New Learning Technologies (2010), pages 5-7.

[7] J. Grodotzki, T. R. Ortelt A. E. Tekkaya, "Remote and Virtual Labs for Engineering Education 4.0: Achievements of the ELLI project at the TU Dortmund University", 46th SME North American Manufacturing Research Conference, NAMRC 46, Texas, USA, Procedia Manufacturing 26 (2018), pages 1355-1356.

[8] D. Galan, L. de la Torre, D. Chaos, E. Aranda, "Combining virtual and remote interactive labs and visual/textual programming: the Furutapendulum experience", Proceedings of the 15th International Conference on Remote Engineering and Virtual Instrumentation (2018), pages 2-4.

[9] S. Frerich, D. Kruse, M. Petermann, A. Kilzer "Virtual labs and remote labs: practical experience for everyone" Engineering Education 4.0 Excellent Teaching and Learning in Engineering Sciences (2016), pages 231-232.

[10] T.Sommer, U.Bach, A.Richert, S.Jeschke, "Engineering education e-learning systems", Engineering Education 4.0 Excellent Teaching and Learning in Engineering Sciences (2016), pages 279-281.

[11] H. Mostefaoui, A. Benachenhou, A. A. Benattia "Design of a low cost remote electronic laboratory suitable for low bandwidth connection. Computer Applications in Engineering Education", Computer applications in Engineering education, 25(3) (2017), pages 487-488.

[12] P. Poulova, M. Černa, L. Svobodova, "University Network - Efficiency of Virtual Mobility", Proceedings of the 5th WSEAS/IASME International Conference on EDUCATIONAL TECHNOLOGIES (EDUTE' 09) (2009), pages 87-92.

[13] G. Ubachs, P. Henderikx, "EADTU Mobility Matrix", European Association of Distance Teaching Universities publication (2018), pages 22-23, available online: https://www.openvirtualmobility.eu/wpcontent/uploads/2018/05/2018_-_EADTU_Mobility_Matrix.pdf, last visit 19.12.2018. 
[14] M. Vriens, M.Achten, W. V. Petegem, J. De Gruyter, I. Op de Beeck, R. Verraest ""Virtual mobility as an alternative or complement to physical mobility" (2010), pages 6-7, available online: https://core.ac.uk/download/pdf/34563482.pdf, last visit: 30.12.2018. 